\title{
IMPACT OF HUMAN RESOURCE COMPONENTS ON ORGANIZATIONAL PERFORMANCE: RESEARCH ANALYSIS
}

\section{RAVI KUMAR ROJA}

Department of Management, Glocal University, Saharanpur, Uttar Pradesh, India

KEYWORDS: Human Resource Management (HRM), Monitory Compensation, Human Resource Management Practices and Organizational Performance
\end{abstract}

Received: Jun 08, 2020; Accepted: Jun 28, 2020; Published: Sep 08, 2020; Paper Id.: IJMPERDJUN20201113

\section{INTRODUCTION}

\section{What is a Human Resource?}

An employee or employees of an organization as part of the total employees as staff in that company is a human resource. Every individual in an entire organization is a human capital who contributes the organization's expertise and knowledge to make the company prosper. Someone able to share their jobs, skills or energy to pay to better the company is a human resource. Whether they are part-time, full-time, autonomous or contract employees, it does not matter. Employees shall be recruited, pleased, inspired, produced and maintained and the work of the human resources team shall be carried out.A department of Human Resources is the one that handles the human capital of an organization. Individuals need better guidance and a different mindset to most tools, so it's worth making a whole team devoted to them. Human Resources Team is qualified to cope avec it, whether it is mediating internal disputes or creating a retirement account.

\section{Working of Human Resource}

The human resources goal is to make the most productive use of the personnel in an organization. Human resources should fix issues like:

\section{Compensation and Benefits}

Compensation is the overall monetary \& non-monetary compensation paid to an individual by an employer in 
the return for jobs completed as required. It's basically a mix of pay, vacation, allowance, life care and other perks that can get, including free lunches, free activities and parking. Such elements are used as compensation is specified. Organizations are dependent on a variety of criteria regarding pay. Certain firms pay more attention than others to the above considerations, but nearly all organizations are using a sort of wage research. They want to pay workers equally in order to promote positive morals, high morale and low unemployment.

\section{Recruiting and Hiring Employee}

Before they can fill a position, the knowledgeable managers who hire the best workers select a pre-qualified group of prospective employees.

\section{Onboarding}

The easiest way to practice and transition to the workforce may be to force new workers onto a new mission. Nonetheless, most jobs in every company demand that procedures be familiar with a certain degree of onboarding. New employee can figure something for themselves, and also in the initial tasks they are knowledgeable. However, as their duties grow, they can be unaware of processes that impede contact in the rest of the business.

\section{Performance Management}

Performance management is the practice of developing a functioning atmosphere in which individuals can do their best. Performance management is a full method of work that starts when a task is established. This comes to an end when an employee leaves the company to find a new career or retire. Each step between these big life cycle activities, performance management determines the relationship with the employee. Growing motivation for contact with an employee is a learning tool for performance management.

\section{Human Resource Management}

Human Resource Management (HRM) encompasses all facets of workplace recruitment and administration of companies (HRM or also abbreviated as HR). The term HRM primarily comes from personal administration, which takes on traditional terms, including the supervision of jobs or health. Throughout the 1980s a number of researchers started focusing on the people of the companies from a new viewpoint, throughout light of an economic crisis and rising market strain because of the globalization and the increased speed of transition brought about by technical advances. A synthesis of this analysis has grown into what has been known as the management of human resources or human resource management.

The main concern of strategic management is how to achieve competitive advantage. Michael Porter's work[1] achieved particular attention in the 1980s. The resource-based viewpoint that arose at this time, a related economic philosophy, assumes that a competitive edge can be gained if the resources of an organization are important, scarce and expensive to be imitated. Both theories affected people management thinking in organizations.

Firstly, people management strategies and programs should be in line with the organization's strategic philosophy [2] and secondly, that all capital and particularly human capital add to organizations' inherent existence, which can therefore foster competitive advantage.

This lead to people being noticed and investing in them as a 'human capital benefit' source, rather than cutting costs. From the organizational behavior theory came the other component of the HRM concept. Organizational behavior 
$(\mathrm{OB})$ is to research the nature and actions of institutions in them. In other words, the interaction between individual and corporate actions and how this effects on the organization's success. HRM's origins in all fields of interest, including the architecture of organizations, the philosophy of association and leadership. The areas of employee engagement and motivation, recently described under "catch-all" employee engagement, are however most crucial to the original concept of HRM.

\section{KEY CHARACTERISTICS OF HUMAN RESOURCES MANAGEMENT}

\section{The Diversity of Human Resources Management}

Specific features of HRM are difficult to define. There are many different models and practices between organizations, often only in a few respects that match the conceptual version of HRM.

\section{The Strategic Nature of Human Resources Management}

The importance attached to strategic integration is perhaps the most important feature of HRM. HR planning therefore needs to comply more generally with organizational planning.

\section{The Commitment-Orientated Nature of Human Resources Management}

HRM is grounded in the ideas of mutuality and strong commitment. If all participants in an organization, they will likely be much more involved and thus perform better and also will work together.

\section{People and their Talents Regarded as Human Capital}

One of HRM's original intellectual principles is that individuals and their mutual talents, expertise and experiences should be seen as a respected commodity and a competitive advantage instead of an expense.

\section{Unitarist rather than Pluralist, Individualist rather than Collective in its Approach to Employee Relations}

The HRM principle claims that workers have the same values as employers and emphasizes the importance not of any agency or entity, but of the connections between the company and the actual employee.

\section{Human Resources Management as a Management-Driven Activity}

While there has been a rise in the amount of HR managers \& the size of HR-departments, HRM is defined as 'a core, managerial, strategic operation which management as a whole has established, owned and run to support their organization. Purcell [3] described it in the early days of HRM as a revival of the management right and Guest [4] said that "HRM is not enough to be left to staff managers." Most recently the role for line managers in meeting HRM goals has been strongly stressed.

\section{An Emphasis on the Needs of the Organization and Business Goals and Values}

The HRM definition was primarily based on a theory of management and industry. Whilst acknowledging the needs of the organization's members, they remain dependent on the interests of the organization. The theory of HRM is therefore emerging in this area. While HR obviously wants to help the accomplishment of corporate goals, there is an increasing belief that HRM has more to do than that. In particular, the needs of all parties and the values \& expectations that society wants to uphold at work must be taken into account by HR. 
The public sector's biggest challenge is to conform to the best practices \& establish the right way of hiring and attracting professional staff to carry out the organization's mission. HRM activity is an important strategic instrument for establishing and maintaining competitive edge in both private as well as public sectors. Organizations have begun to realize that human resources can achieve a competitive advantage. Research into corporate participation in the provision of public services has now been critical as this is done.To create a socially stable and cohesive society, access to appropriate and accessible public resources is essential. Connections between service environment and customer satisfaction have been identified. The scientific theory is focused on business market studies, where consumers are easily happy and more likely to return to the enterprise if companies foster an environment that rewards workers for their commitment to customer service.

In fact, the principle of services environment indicates that workers are more likely to deliver better care to their clients, as their company is viewed as having respect both for staff and consumers. The theoretical philosophy of human management is often based on the premise that effective management strategies and procedures boost company efficiency. Strategic human resources theory suggests that the commitment of an company to a market for operation would increase its comparative edge if it uses its HRM activities effectively[5].

\section{What constitutes Human Resources Practices?}

'There is no technique that can be called an HR activity which addresses enhanced skills, productivity, engagement and culture. This may take the shape of a program, a procedure, an operation, a law or just a way to do stuff. The success of the company is dictated by good human resources activities. Good practices in the area of human resources are those that contribute to one or more C's: competencies, commitments and culture. It must be defined and cost-effectively applied, checked and updated from time to time to improve their efficiency and adequacy.

According to Yeung and Berman [6] HR practices can play three major roles, these roles are:

- $\quad$ Building critical organizational capabilities

- Enhancing employee satisfaction

- Improving customer and shareholder satisfaction

Effective human resources activities impact the organization's operating performance. Strengthen an organization's internal ability to resolve existing or future problems. Good standards in human resources also contribute to the well-being of company workers.

Effective human resources can add to hard work \& can impact the organization as well, due to their diligence and inspiration. This program, built up of strong human resources practices, will build the organization's viable and long-term potential for internal management and external challenges.

\section{Human Resources Practices include:}

- HR Planning

- $\quad$ Recruitment \& Selection

- Induction 
- Training \& Development

- Performance Appraisal

- Career Planning

- Fringe Benefits

- Reward \& Recognition

- Introduction to HR Practices

- Welfare Activities as per Statutory Requirement

- Safety, Health and Environment Policy

- Suggestions Scheme

- Promotion \& Transfers

- Exit Policy.

HR Activities affect the employee's job success constantly and dramatically. Excellent activities in the sector will tackle issues such as a growing influx of workers, changing markets, traditions, transformation and the potentially deleterious impact of technology. The organization's growing human resource policies will continue to reduce the workforce's spending as its efficiency improves.Therefore these changes are expected to be effectively implemented by HR managers to improve the company. The efficiency of internal management procedures greatly increases by adopting some of the creative HR activities.

\section{Main Strategies in Human Resources Activities to Better Produce Efficiency include:}

- Establish a team of operational excellence to improve continuously

- Set criteria to ensure continuity around the HR feature

- Manage processes from the end-to-end term

- $\quad$ Rationalize HR applications

- Design of advanced learning educational systems

- Strict governance mechanisms are developed to enhance financial management and transparency to improve efficiency and enforcement

- Test HR efficiency against expectations in industry

- Communicate to the organization and bring value by taking pragmatic actions.

\section{Human Resources and Performance}

The continuing challenge for HR has been to show that good HR practice leads to improved corporate results in addition to being good. It will be shown to prove that HR does not reflect 'add value' expenses for the company. Thinking here is 
based on the idea that the morale and dedication of workers are strengthened by successful HR activities that have a significant effect on efficiency and performance.

\section{Firms Performance}

Company efficiency was thoroughly reviewed in the past. Several financial metrics that assess the company's success include efficiency, competitiveness and revenue. Resources manager (HRM) is a core business problem which has influenced employee behavior, perceptions which efficiency, and scholars such as Noe, Hollenbeck, Gerhart and Wright [7] concluded that HRM is important tools for corporate success. In the case of employees not being engaged in their businesses, productivity would be reduced, the poor service quality provided, business opportunities lost, and the administrative burden for companies subsequently increased.

In previous studies, HR activities were correlated with lower attrition of staff, greater workplace participation and increased employee skills and attitudes (Wright, Gardner, Moynihan, \& Allen)[8]. The effect of HR strategies on the organisation's success has been found. The study on HR activities centered on developing economies. The work was witnessed. It is important, because developing countries are not exactly comparable with Western areas of the world, to research the impact of HR activities on employee efficiency.

\section{Incentives}

Miller and Whitford [9] asserted that, in light of the comprehensive analysis undertaken in principal agency theory, opportunities have improved dramatically. Past researchers have discovered that a close link exists between management motivation and risk control, thus contributing to improved organizational results. Within the literature the position of behavior incentives has been well established. Incentives are offered in the form of cash incentives or other incentive award forms, such as stock shares, shareholding, awards and bonuses.

The efficiency of workers is greatly increased by compensation programs backed by positive and creative work processes. The study's analytical model is based on the organization hypothesis that the risk-neutral members choose their director to increase the profits of firms. This research thus uses the analytical paradigm of agency theory to help understand whether rewards are to serve as referees in terms of the effect on organizational efficiency.

\section{Employee Training}

Past researchers have found evidence on the impact of training on productivity and where employees and employers were able to share the benefits from training [10].

\section{Performance Appraisal}

Comprehensive performance appraisal system forms the basic yardstick for assessing an individual's performance, highlight potential for future career advancement, most importantly, to improve the performance. Lecky [11] defined performance appraisal system as a benchmark which is set against specific task performance, define and evaluate current performance. It requires the input and output such as remuneration, pay rise, level of expectation, promotion and managerial planning. In addition, it is a merit rating which should be beneficial to both parties and must be constantly reviewed to suit the requirement. The system explicitly mentioned the individual's needs and thus has far reaching effect of improving productivity. 


\section{FEW COMPONENTS OF HUMAN RESOURCE MANAGEMENT}

\section{Training and Employee Development}

Education is undertaken to bring change to the organization's community by introducing a new employee. New workers must learn new skills or develop their abilities to enable the transition a company wants. Training is not enough to inspire men. However, an organization is an effective tool to accomplish its long-term objectives Laird, Holton \& Naquin [12]. Workplace preparation shall be undertaken as a way of maintaining the organizational culture and positive practices which will in effect be compensated and awareness.

Education often plays a major role for employees because it is an integral aspect of the employee's career cycle within a company. The skills learned through education. Training as an instrument will help an employee improve his skills and techniques and improve his organizational performance. Training plays a significant role in inspiring workers to engage in coordinated initiatives, actively endorsing efforts to strengthen the organization, and doing everything possible to accomplish organizational objectives.

\section{Performance Appraisal}

To order to recompense staff for the contributions of Collins and Clark [13], companies are using efficiency reviews. Performance evaluation has both a direct and an indirect influence on workplace administrative efficiency and input from performance review events, which are typically performed at least once a year, may help to enhance administrative processes.

\section{The Goals of HRM}

- Help the organization's priorities by designing and executing HR approaches incorporated into the plan

- Contribute to the creation of a high-performance community

- $\quad$ Entertain the creative, trained and dedicated people required for the company

- Building a productive employee-management partnership and atmosphere of shared confidence

- $\quad$ Foster the use of a rational approach to treating employee.

\section{Types of HR Strategy}

Wide announcements of intent on the organization's HR. Also known as an 'umbrella strategy.' The main factors will include the creation of a good culture of success, improvement of leadership, the recruitment and retention of talent, and the improvement of HR programs.

- HR approaches focused on common HR templates, like 'High Leistung Management'

- HR approaches in particular areas, such as leadership acquisition or learning and growth methods.

\section{Criteria with Regard to HR Strategies}

- It satisfies organization needs

- It is investigated and based on evidence, not merely wonders

- It may be turned into actionable initiatives 
- Its components are coherent $\&$ integrated

- It takes all stakeholders of the company into account and does not represent exclusively the opinions of the senior management or the HR role, for example.

During the Process of HR Strategy Formulation, the Following Questions about the Workforce are Useful to Ask [14]:

- What causes people to come to work?

- What motivates them to perform?

- What stops them from being effective?

- $\quad$ Are they engaged?

- Do they know the big picture?

- Is their potential harnessed?

The above questions aids the organization as well as individual to explore and think of a bigger picture. When making strategies these type of question help an individual in raising their performance. With the help of the experimentation this research paper tries to find out the relation between different components of the human resource management (HRM) such as training and information with the organizational as well as individual performances. This will help to determine how the performance of the company varies because of the correct execution of the human resources.

\section{RESEARCH QUESTION}

What are the impacts of human resource practices such as performance appraisal, training and information technology along with the incentives over the performance of the organization?

\section{LITERATURE REVIEW}

There have been handful of researches that helps to determine, that is there any direct relationship between the human resource management and the performance of the organization. AnanthalakshmiMahadevan and Fadumo Ahmed Mohamed both the lecturers of in Malaysia conducted a research work in order to identify the impact of HRM practices such as Compensation, employee participation and training on the employee's performance. The research paper titled as "Impact of Human Resource Management (HRM) practices on Employee" [15]had details of the research work conducted by both the authors. The study was based on Malaysia where about 102 employees were selected in order to fill the questionnaire for testing specific hypothesis. In order to find out the impact of variables on employees performance the regression analysis was taken using SPSS. The outcome of the experiment showed that there existed a major relationship between the compensation plans on employee performance and impact of training. However the experiment was limited to a single telecom based company in Malaysia so the results cannot be rationalized. These HR practices are based on research by various researchers and according to the main HR practice at Telekom Malaysia several other practices could be concentrated in future studies.

Based on 171 large manufacturing firms in Malaysia an experiment was conducted in order to examine the direct relation between the human resource practices (HRM) such as performance appraisal, training, recruitment, reward system 
and career management. The researchers named Cheng Ling Tan and AizzatMohdNasurdin conducted this research and created a research paper titled "Organizational Innovation: Assessing the Mediating Role of Knowledge Management Effectiveness[16]. The results of the experiment showed that HRM practices normally have good impact over organization performance and innovation. Training of the employees came out to be the most effective tool for organization performance.

\section{METHODOLOGY}

\section{Design}

The experiment was designed in such a manner that the result can be as accurate as possible. In order to get rationalized results the city of Bengaluru was chosen. The city is nick named as cyber capital of India accommodating people of varying locations across the country. This helps the research to get more general and accurate results. After selecting the location, the employees of IT companies were chosen who were given set of questionnaires. The responses were determined in tabular form in order to analyze them correctly.

\section{Sample}

The study's population is comprised of IT companies located in Bengaluru, India, with the aim of generalizing businesses in Bengaluru. The IT sector is currently seen as a pillar of the plan for Indian economic diversification. The investigator in Bengaluru selected large IT companies using comfortable sampling methods. 100 sets of questionnaires were given to IT administrators in Bengaluru, but only 60 copies of the questionnaire could be used for study.

\section{Instrument}

There are three sections of the questionnaire used in this analysis. Section 1 allowed respondents to score the three HRM elements, i.e. rewards, performance evaluation\& IT, at a total of 10 items. Incentive issues such as incentives increase individual material wealth and incentives are asked to increase economic interest in the company.

In Section 2, on the other hand, there were four questions related to corporate efficiency. Of examples, issues like corporate success are related to the rise in profits from transactions, company performance is calculated by growing profit levels, and corporate performance is related to a higher market share figure. The respondents were asked to describe the scale at 7 point scale: $1=$ very much in agreement, $2=$ in agreement, $3=$ somewhat in agreement, $4=$ neutral, $5=$ somewhat in disaccord, $6=$ in disagreement, 7 = strongly disagreement.In addition, personal $\&$ demographic data were gathered about age, class, ethnicity, working hours, academic performance, gross monthly salary, location in the workforce and industry.

\section{Data Collection}

The information about the demography of respondents, including gender, age, education, work experience, monthly gross pay and so on, as indicated in Table 1. Table 1 shows 18 interviewees' characteristics in the survey. Gender allocation was relatively equal with 25 male $(50 \%)$ and 25 female $(50 \%)$ respondents. The vast majority of the 50 people surveyed were Indians.

Of the survey overall, $19(38 \%)$ respondents were employed in the BPO sector, $15(30 \%)$ in the research and development and $8(16 \%)$ in Administration and the remaining $5(10 \%)$ and $3(6 \%)$ in other sectors.

Furthermore, 20 of them (40\%) had lower management tiers, while $30(60 \%)$ had middle management tiers and above. The alphas for the Cronbach HRM coefficients varied between.72 and.90, which is clearly appropriate. While 
normal variables either were close or exceeded 1.0, the sample variables were unequal. All of the four things reflecting the Cronbach coefficients alpha of.83 have maintained the company's results. In addition, the values showed that the Grouping items reliability of both variables was reasonable internal accuracy estimation.

Table 1: The Table Carries the Demographic and Other Details of the Sample that was used to Execute the Research Work

\begin{tabular}{|l|c|c|c|}
\hline \multicolumn{2}{|c|}{ Demographic Characteristics } & Strength & Percentage (\%) \\
\hline \multirow{2}{*}{ Gender } & Male & 25 & 50 \\
\cline { 2 - 4 } & Female & 25 & 50 \\
\hline \multirow{4}{*}{ Age } & $<22$ & 14 & 28 \\
\cline { 2 - 4 } & $22-30$ & 21 & 42 \\
\cline { 2 - 4 } & $30-40$ & 8 & 16 \\
\cline { 2 - 4 } & $40-50$ & 7 & 14 \\
\hline \multirow{3}{*}{$\begin{array}{l}\text { Year with } \\
\text { organization }\end{array}$} & $<5$ & 10 & 20 \\
\hline \multirow{4}{*}{\begin{tabular}{l} 
Sector \\
\cline { 2 - 4 }
\end{tabular}} & $5-10$ & 17 & 34 \\
\cline { 2 - 4 } & $10-15$ & 6 & 12 \\
\cline { 2 - 4 } & BPO sector & 17 & 34 \\
\cline { 2 - 4 } & R and D & 9 & 18 \\
\cline { 2 - 4 } & Administration & 12 & 24 \\
\hline
\end{tabular}

Table 2: The Table Possess Results of the Reliability Analysis

\begin{tabular}{|l|c|}
\hline \multicolumn{1}{|c|}{ Variables } & Cronbach's Alpha \\
\hline Reward & .72 \\
\hline Information Technology & .85 \\
\hline Performance Evaluation & .90 \\
\hline Performance of Organization & .81 \\
\hline
\end{tabular}

Table 3: Pearson Correlation has been done for Human Resource Management (HRM) and Firm Performance Measure

\begin{tabular}{|l|c|c|c|c|}
\hline \multicolumn{1}{c|}{ Variables } & $\mathbf{1}$ & $\mathbf{2}$ & $\mathbf{3}$ & $\mathbf{4}$ \\
\hline Reward & 1.00 & & & \\
\hline Information Technology & .29 & 1.00 & & \\
\hline Performance Evaluation & .45 & .26 & 1.00 & \\
\hline Performance of Organization & .32 & .49 & .44 & 1.00 \\
\hline
\end{tabular}

The immediate and moderating impacts of HR activities, opportunities and organization's success were measured in a 3-stage hierarchical multi-return review. The goal of hierarchical regression is to just get details on the way the variables connect. The findings of the analyzes are listed in Table 4. Steps 1 and 2 were found to be significant as indicated in Table $4(\mathrm{p}<0.1)$.

Table 4: Regression Results by Utilizing Rewards as the Moderator Between HRM Factors and Organizational Performance

\begin{tabular}{|l|l|c|c|c|}
\hline \multicolumn{2}{|c|}{ Variables } & Step 1 & Step 2 & Step 3 \\
\hline \multirow{3}{*}{ Model Variables } & Information Technology & .27 & .21 & 1.45 \\
\cline { 2 - 5 } & Performance Evaluation & .31 & -.18 & -.39 \\
\cline { 2 - 5 } & Performance of Organization & .24 & .24 & -.85 \\
\hline Reward & Information Technology & & .44 & .52 \\
\hline \multirow{2}{*}{ Interaction Terms } & Performance Evaluation & & -1.65 \\
\cline { 2 - 5 } & & & .68 \\
\hline
\end{tabular}




\begin{tabular}{|l|l|c|c|c|}
\hline & Performance of Organization & & & 1.15 \\
\hline $\mathrm{R}^{\wedge} 2$ & .32 & .41 & .43 \\
\hline Adj $\mathrm{R}^{\wedge} 2$ & .27 & .39 & .39 \\
\hline $\mathrm{R}^{\wedge} 2$ change & .29 & .11 & .02 \\
\hline F value & 14.52 & 15.84 & 1.03 \\
\hline
\end{tabular}

\section{DATA ANALYSIS}

Table 2 summarizes the results of the reliability analysis. Table 3 displays the inter-relationships of the subscales obtained. The inter-correlation values between the predictor variables were generally small, ranging between the variables.26 to.45 $(\mathrm{p}<.01)$, thus indicating the scales that used to measure the predictors were independent. Furthermore, there was a significant correlation of a number of predictor variables with the dependent variable varying from.32 to.49, which was considered as narrow interrelationship values. Scales used to calculate the predictors independence.

Therefore, $31 \%$ and $40 \%$ of the occupational volatility is greatly explained by the direct effects of predictors. The study also showed that, at $\mathrm{p}<.01), 30(\mathrm{p}<0.1)$, and AND-035 $(\mathrm{P}<.01)$, there was an important correlation for two aspects in HR operation, including information technology, preparation for workers and rewards.

\section{RESULTS \& DISCUSSIONS}

A pattern of relations between the human resource (HR) and organizational performance was suggested by this study. Factors such as IT, staff training and incentives have been demonstrated to have made a positive contribution to performance of the organization. At the other side the correlation between HRM and organizational success was not moderated by incentives. This was unexpected. In other terms, corporate efficiency may be improved without the need to provide rewards as the company has a successful HR program.

This research lets people understand the effect on corporate success of HR activities. Previous study suggests that organizations with HRM skills are more likely to improve their operational efficiency but that the causal correlation between HR experience and business success was not moderated by corporate opportunities. This work also adds to current HRM studies focused on HRM and opportunities.

\section{CONCLUSIONS}

The purpose of this paper was to study the impact of HR activities by focusing on three corporate success metrics in India. Ironically, the IT and employee recruitment and benefit links to organizational effectiveness have been clear and substantial.This could be because employees really aren't paid in comparison with most developing countries, as in developed countries, so they are much more interested in human resources activities that may then improve earnings. Personnel incentives have an effect primarily on organizational performance, instead on the relationship between HR policies and performance.With regard to the direct effects on organizational profitability, knowledge management, jobs and compensation, these practices are crucial indicators to maximize corporate performance. IT is also vital, on the other hand, for customer efficiency optimization. Staff do not respond solely to financial incentives, as other non-financial incentives are equally essential, such as the confidence, duty and prestige of groups and communities.

That may be possibly because 'high-powered' incentives like market purchases and 'low-powered' incentives in bureaucracy have played a role in that. The association between HR and organizational behavior, however, was not diminished by incentives. It is most likely because the readiness to perform and achieve improved organizational 
performance depends on compliance with collectivity-based actions, which is typical in Asian countries.In addition, past studies in a cross-cultural study support this finding that employee confidence behavior based on effect is correlated with employee entrepreneurial behavior; therefore the business rewards do not mitigate the correlation between HR activities and their levels of business performity. Interestingly, the findings indicate that staff preparation and evaluation of success are associated with improved organizational performance. This is not surprising, as previous literature on the wage impact of education and training showed conflicting results.

The study has demonstrated that there are strong positive correlating values for HRM determinants like IT, training and corporate incentives. This shows that, above all the assessments made by companies, employes value incentives and IT training. Such findings were consistent with prior study findings which enhance companies' performance by ensuring self-growth and independence at work.The aim of management development efforts is to educate managers in certain functional fields about the different type of human resources practice, such as running workshops as well as training sessions for managers and supervisors, which would actually be most effective for employees on a long-term basis.

\section{REFERENCES}

1. T. FME, "Porter's Five Forces," Strategy, 2011.

2. C. J. F. N. M. T. M. A. Devanna, Strategic human resource management..

3. J. Purcell, "MAPPING MANAGEMENT STYLES IN EMPLOYEE RELATIONS,” J. Manag. Stud., 1987.

4. D. E. Guest, "Human resource management and performance: Still searching for some answers," Hum. Resour. Manag. J., 2011.

5. A. Towler, D. V. Lezotte, and M. J. Burke, "The service climate-firm performance chain: The role of customer retention," Hum. Resour. Manage., 2011.

6. A. K. Yeung and B. Berman, "Adding value through human resources: Reorienting human resource measurement to drive business performance," Human Resource Management. 1997.

7. P. W. Raymond Noe, John Hollenbeck, Barry Gerhart, Human Resource Management..

8. P. M. Wright, T. M. Gardner, L. M. Moynihan, and M. R. Allen, "The relationship between HR practices and firm performance: Examining causal order," Pers. Psychol., 2005.

9. G. J. Miller and A. B. Whitford, "The Principal's Moral Hazard: Constraints on the use of Incentives in Hierarchy," SSRN Electron. J., 2011.

10. L. Dearden, H. Reed, and J. Van Reenen, "The impact of training on productivity and wages: Evidence from British Panel Data," Oxf. Bull. Econ. Stat., 2006.

11. A. Cook and J. Leckey, "Do expectations meet reality? A survey of changes in first-year student opinion," J. Furth. High. Educ., 1999.

12. S. S. N. Dugan Laird, Elwood F. Holton, Approaches To Training And Development..

13. C. J. Collins and K. D. Clark, "Strategic human resource practices, top management team social networks, and firm performance: The role of human resource practices in creating organizational competitive advantage," Academy of Management Journal. 2003.

14. J. T. Reilly et al., "Guideline for the diagnosis and management of myelofibrosis," Br. J. Haematol., 2012. 
15. F. A. M. Ananthalakshmi Mahadevan, "IMPACT OF HUMAN RESOURCE MANAGEMENT (HRM) PRACTICES ON EMPLOYEE PERFORMANCE,” Int. J. Account. Bus. Manag., vol. 2, no. 2, p. 14, 2014.

16. C. Tan and A. Nasurdin, "Human resource management practices and organizational innovation: assessing the mediating role of knowledge management effectiveness," Electron. J. Knowl. Manag., 2011. 
